\title{
Characteristics of ambulatory care visits to family medicine specialists in Taiwan: a nationwide analysis
}

An-Min Lynn, Tzu-Chien Shih, Cheng-Hao Hung, Ming-Hwai Lin, Shinn-Jang Hwang, Tzeng-Ji Chen

Although family medicine (FM) is the most commonly practiced specialty among all the medical specialties, its practice patterns have seldom been analyzed. Looking at data from Taiwan's National Health Insurance Research Database, the current study analyzed ambulatory visits to FM specialists nationwide. From a sample dataset that randomly sampled one out of every 500 cases among a total of 309,880,000 visits in 2012, it was found that $18.8 \%$ ( $n=116,551$ ) of the 619,760 visits in the dataset were made to FM specialists. Most of the FM services were performed by male FM physicians. Elderly patients above 80 years of age accounted for only $7.1 \%$ of FM visits. The most frequent diagnoses (22.8\%) were associated acute upper respiratory infections (including ICD 460, 465 and 466 ). Anti-histamine agents were prescribed in $25.6 \%$ of FM visits. Hypertension, diabetes and dyslipidemia were the causes of $20.7 \%$ of the ambulatory visits made to FM specialists of all types, while those conditions accounted for only $10.6 \%$ of visits to FM clinics. The study demonstrated the relatively low proportion of chronic diseases that was managed in FM clinics in Taiwan, and our detailed results could contribute to evidencebased discussions on healthcare policymaking and residency training. 


\section{Article}

2 Characteristics of ambulatory care visits to family medicine 3 specialists in Taiwan: a nationwide analysis

4 An-Min Lynn ${ }^{1,2}$, Tzu-Chien Shih", ${ }^{1,2}$, Cheng-Hao Hung ${ }^{1,2}$,Ming-Hwai Lin ${ }^{1,2, *}$, Shinn-Jang 5 Hwang ${ }^{1,2}$, and Tzeng-Ji Chen ${ }^{1,2}$

61 Department of Family Medicine, Taipei Veterans General Hospital, No. 201, Sec. 2, Shi-Pai

7 Road, Taipei 112, Taiwan

82 School of Medicine, National Yang-Ming University, No.155, Sec.2, Linong Street, Taipei,

9 112, Taiwan

10 * Author to whom correspondence should be addressed; E-Mail: minghwai@gmail.com;

11 Tel.: +886-2-2875-7458; Fax: +886-2-2873-7901.

12

13

14

Academic Editor:

Received: / Accepted: /Published:

Abstract: Although family medicine (FM) is the most commonly practiced
specialty among all the medical specialties, its practice patterns have seldom been
analyzed. Looking at data from Taiwan's National Health Insurance Research
Database, the current study analyzed ambulatory visits to FM specialists nationwide.
From a sample dataset that randomly sampled one out of every 500 cases
among a total of $309,880,000$ visits in 2012 , it was found that $18.8 \%$ (n $=116,551)$
of the 619,760 visits in the dataset were made to FM specialists. Most of the FM
services were performed by male FM physicians. Elderly patients above 80 years of
age accounted for only $7.1 \%$ of FM visits. The most frequent diagnoses $(22.8 \%)$
were associated acute upper respiratory infections (including ICD 460,465 and 466$)$.
Anti-histamine agents were prescribed in $25.6 \%$ of FM visits. Hypertension, diabetes
and dyslipidemia were the causes of $20.7 \%$ of the ambulatory visits made to FM
specialists of all types, while these three chronic diseases accounted for only $10.6 \%$
of visits to FM clinics. The study demonstrated the relatively low proportion of
chronic diseases and adult preventive care that was managed in FM clinics in
Taiwan, and our detailed results could contribute to evidence-based discussions on
healthcare policymaking and residency training.




\section{Introduction}

Family medicine (FM) specialists act as general practitioners and provide primary care services in the community, including solving minor cases, making referrals for major diseases, and providing and promoting preventive health services. Because of an overemphasis on medical specialization over the past several decades, the importance of FM specialists has been increasingly noticed in terms of the benefits they provide to patients [Ryan et al., 2001; Shi et al., 2003; Baicker \& Chandra, 2004; Cooper, 2009a; Cooper, 2009b; Baicker \& Chandra, 2009]. The associated issues, such as the practicing environments of FM specialists and primary care reforms, also affect the government's finances and public health [Bindman \& Majeed, 2003; Van \& Del, 2004; Chou et al., 2007; Skinner et al., 2009; Chang et al., 2011; Katz et al., 2012;]. On the other hand, the aging societies and inequalities in health care have increased the complexity of constructing deliberate health policies [Beckman \& Anell, 2013; Jin K, 2014]. Comprehensive information about family medicine care is essential to the analysis of existing problems. In the United States, the Primary Care Network Survey and National Ambulatory Medical Care Survey (NAMCS) have been useful in this regard in terms of indicating the number of ambulatory visits to primary care clinics and delineating the national profile of primary care [Cypress et al., 1982; Cypress et al., 1983a; Cypress et al., 1983b; Cantrell, Young \& Martin, 2002; Binns et al., 2007]. Information from Canadian physicians has also proved valuable in this regard [Cunningham et al., 2014]. Other countries have also reported on the working status of practicing FMS [Okkes et al., 2002; Emmanue, Phua \& Cheong, 2004; Aboulghate et al., 2013; Raza et al., 2014; Granja, Ponte \& Cavadas, 2014]. Nevertheless, literature looking at the practice of FM on a nationwide basis remains sparse in most countries, including Taiwan.

The purpose of the current study was to explore the nationwide characteristics of ambulatory visits to FM clinics recorded by Taiwan's National Health Insurance (NHI) system in 2012. We analyzed the ages and genders of the patients and physicians, the procedures conducted, diagnoses made, and medications prescribed during these visits. The findings may offer valuable information for future discussions on healthcare policymaking and FM residency training programs, and may also provide a foundation for making international comparisons.

\section{Materials \& Methods}

\subsection{Database}

The NHI program in Taiwan, which started in 1995, provides comprehensive healthcare coverage to more than $99 \%$ of the country's residents. The National Health Insurance Administration of the Ministry of Health and Welfare has released all de-identified claims data dating back to 1999 for academic research in the form of the National Health Insurance Research Database (NHIRD; http://w3.nhri.org.tw/nhird/). The conduct of the study had been approved by the institutional review board (IRB) of Taipei Veterans General Hospital, Taipei, Taiwan (2013- 
04-005E). Because of anonymized data that are publicly available on application, our study is exempt from full IRB review.

\subsection{Study Population}

We performed a descriptive and cross-sectional study by accessing the sampling files for the year 2012 (S_CD20120.DAT and S_OO20120.DAT of NHIRD). In the terminology of NHIRD, the dataset "CD" is defined as the collection of all outpatient visit files, while the "OO" dataset comprises the outpatient order files. According to NHIRD, the size of subset from each month is determined by the ratio of the amount of data to that of the entire year. Then the systemic sampling is performed for each month to randomly choose a representative subset. A sampling database is obtained by combining the subsets from 12 months. The sampling database of S_CD20120 was constructed at first, and then the relative observations in S_OO20120 were drawn out accordingly. These two sampling files, which exclude information on visits to dental clinics and traditional Chinese medicine clinics, contain a total of 619,760 medical records, and were obtained by a $0.2 \%$ sampling ratio from the $\mathrm{CD}$ and $\mathrm{OO}$ datasets for 2012. Each individual record included the patient's identification number, birth date, gender, medical facility, date of visit, the specialty of the consulting physician, and up to three diagnosis codes as defined by the International Classification of Diseases, Ninth Revision, Clinical Modification (ICD-9-CM).

From the sampling data, the details of 116,551 ambulatory visits to FM specialists were extracted and analyzed. A list of reimbursable drugs with additional coding in the Anatomical Therapeutic Chemical (ATC) classification system (http://www.whocc.no/atc ddd index/) was provided by the National Health Insurance Administration. The basic data of the contracted medical care institutions presented the status of accreditation: academic medical center, metropolitan hospital, local community hospital, or physician clinic. We also analyzed the diagnoses made, procedures conducted, and medications prescribed during the visits to facilities of various levels.

\subsection{Statistical Analysis}

The programming software Perl version 5.20.2 (produced by Perl) was used for data processing, and regular descriptive statistics were displayed.

\section{Results}

Based on the sampling data, of the 619,760 ambulatory visits made in $2012,18.8 \%$ ( $\mathrm{n}=$ 116,551) were made to FM specialists-making FM the most commonly utilized specialty 
102

103

104

among all physician specialties (Table 1). FM also accounted for $8.3 \%$ of insurance claims, with those claims amounting to an estimated NT\$309 billion in 2012.

Among the ambulatory visits to FM specialists, 53.1\% were made by female patients ( $\mathrm{n}=$ $61,974)$ and $46.9 \%$ were made by male patients $(n=54,577)$. Stratifying the records by age group demonstrated that patients aged 50-59 years had the highest proportion of ambulatory visits to FM specialists among both genders (male: 18.0\%, $\mathrm{n}=9,855$; female: $19.2 \%, \mathrm{n}=$ 11,955), followed by patients aged 60-69 years among both genders (male: $15.3 \%, \mathrm{n}=8,360$; female: $16.5 \%, \mathrm{n}=10,641$ ) in Fig 1 . No remarkable gap in the number of visits was evident between the various age groups, except that the number of visits by patients aged 80-89 years and 90-99 years dropped obviously from the numbers of visits made by all the other younger groups.

The number of ambulatory visits to FM specialists in terms of the physicians' gender and age is presented in Fig 2. These data indicated that there are far fewer female physicians than male physicians in all the age ranges. Compared with the other working-age age ranges, the number of female physicians was the highest in the 30-39 years $(n=3,806)$ range, although the number of female physicians in that range was still below the number of male physicians in that age range.

In the current investigation, FM clinics remained the major ambulatory care providers, handling $89.9 \%(\mathrm{n}=104,796)$ of the ambulatory visits to FM, followed by metropolitan hospitals (4.1\%), local community hospitals $(3.7 \%)$, and academic medical centers $(2.3 \%)$. Among the ambulatory visits to FM specialists, $65.5 \%(\mathrm{n}=76,392)$ produced only one diagnosis. The top 10 most common diagnosis groups (based on the first diagnosis code in every medical record) are listed in Table 2. The top diagnosis was acute upper respiratory infection (13.1\%), followed by essential hypertension (9.9\%), general symptoms (6.9\%), acute bronchitis and bronchiolitis $(5.9 \%)$, and diabetes mellitus $(5.7 \%)$. The ranking of the diagnosis groups varied according to hospital level.

In general, the most common procedures performed during ambulatory visits to FM were checks of glucose $(3.7 \%, n=4,269)$, cholesterol, $(2.3 \%, n=2,719)$, triglyceride $(2.2 \%, n=$ 2,599), S-GPT/ALT $(1.9 \%, n=2,270)$, serum creatinine $(7.8 \%, n=2,802)$, and HbA1c $(1.5 \%, n$ $=1,781)$ levels. The application of the procedures had high consistency between the ambulatory care settings (Table 3 ). 
137 Of the ambulatory visits to FM specialists, $89.4 \%(n=104,171)$ included the prescribing of 138 medication. Approximately 55.8\% of the visits where medication was prescribed recorded 139 prescriptions of three or more drugs (one drug $15.8 \%$, two drugs $17.8 \%$, three drugs $19.6 \%$, four 140 drugs $16.9 \%$, five drugs $10.4 \%$, six drugs $5.0 \%$, seven or more drugs $3.9 \%$ ). The most commonly 141 prescribed medications were anti-histamines for systemic use (25.6\%), non-steroid anti142 inflammatory and anti-rheumatic products (24.6\%), and other analgesics and anti-pyretics 143 (24.5\%) (Table 4).

\section{Discussion}

147 In this report, FM clinics remained the primary ambulatory care providers, receiving $89.9 \%(n$ $148=104,796)$ of the ambulatory visits to FM clinics. This finding reveals that primary medical 149 facilities are responsible for most of the FM specialists' workloads. Indeed, all of the top 10 150 diseases can be managed by FM clinics. In other words, the character of ambulatory visits meets 151 the expectation of primary medical care for minor conditions. However, the number of visits 152 from patients aged over 80 years has markedly decreased. To our knowledge, multiple 153 comorbidity and polypharmacy are prominent in this age group, and both conditions are 154 prevalent in Taiwan [Lai et al., 1995; Chan, Hao \& Wu, 2009; Lin, Wang \& Bai CH, 2011]. 155 These issues may have contributed to many patients in this age group being too weak to visit FM 156 clinics and being transferred to other departments after being admitted for severe illnesses or 157 comorbidities. In Taiwan, any transfer to a lower class accommodation is not popular. Therefore, 158 patients aged over 80 years make fewer visits to FM clinics but make more visits to other types 159 of specialists in hospitals instead. This suggests that developing and implementing a referral 160 system policy for home medicine is vital.

We found among patients aged 30-79 years women paid more visits to FM specialists than men. Some studies of health seeking behaviors revealed that female patients were more interested in health-related information and paid more attention to their own life, including ambulatory visits [Ek, 2013; Galdas, Cheater \& Marshall, 2005; Oliver MI et al., 2005]. On the other hand, among patients aged 0-29 years in our study male had more visits. It was unclear whether younger male patients had more risky behaviors or were more susceptible to fall ill. Besides, parents might decide the seeking health behaviors of children [Chen HY et al., 2012] and boys usually received more attention than girls.

In addition, the number of visits to FM clinics regarding chronic diseases such as 172 hypertension (ICD 401), diabetes mellitus (250) and dyslipidemia (272) was less than half the 
173 number of such visits to other facilities. This suggests that patients prefer to receive regular 174 medical treatment for chronic diseases in hospitals rather than in FM clinics, and that clinic 175 physicians may not pay particular attention to chronic diseases, possibly due to benefit payments, 176 the large number of waiting patients at the clinic, or a lack of concepts of holistic care. In the 177 NHI program, no matter how much time a physician spends with a patient, the physician receives 178 the same reimbursement. Therefore, doctors generally appear not to do so much health 179 counseling or education to identify potential patients with chronic diseases [American Institute in 180 Taiwan]. The government bodies have to innovate the methods of claims to encourage 181 physicians to pay attention holistically [Michael Barr, American College of Physicians. 2006] 182 and so that preventive care can be provided. It is also necessary to educate members of the public 183 so that they understand that the diagnosis and treatment of these diseases can be handled by FM 184 clinics. Surely, since the highest number of patients visiting FM clinics consists of those aged 185 50-59 years, continuing medical education, with appropriate approaches and referrals, also needs 186 to be ensured.

187

In our study, female physicians accounted for a small amount of visits to FM clinics. The gender disparity increased with age (Fig. 2). The reason might be that fewer women became physicians in the past (Taiwan Medical Association). Another finding was that the majority of visits were made to FM specialists aged 50-59 years. That is, the FM workforce in Taiwan was aging, a phenomenon also observed in obstetrician-gynecologists [Lynn AM et al., 2015].

Resident doctors may have abundant training in academic areas, but they should also have clear insights regarding real-world experiences and, maybe, related lessons. FM specialists should not only manage upper respiratory infections but should also manage geriatric conditions, demonstrate healthy behaviors, including good diets and exercise, and adequately perform health counseling in their future practice. This may encourage medical students to consider all the facts in choosing a career or calling, rather than working exclusively with the common cold.

As for the subject of medication, anti-histamine agents are prescribed most often. Since the NHI program has limited the use of antibiotics for URI or common colds since 2001, antibiotics did not show up among the top 10 most prescribed medications. Symptomatic agents including NSAIDs, antipyretics, expectorants, and cough suppressants were all used for URI. However, antacids are still prescribed often (12.5\%), even though the percentage of gastritis diagnoses $(3.5 \%)$ was not as high as the medication usage. This is because many patients believe they need antacid to protect their stomachs from medicine damage [Chen, Chou \& Hwang SJ, 2003]. To decrease the related expenses and potential drug-drug interactions, it is important to educate both the public and physicians that overuse of antacids is not good for the body and that real GI discomfort needs to be diagnosed and treated separately. 
The medical care expenses claimed by FM specialists accounted for $8.3 \%$ of the total

213

214

215

216

217

218

219

220

221

222

223

224

225

226

227

228

229

230

231

232

233

234

235

236

237

238

239

240

241

242 ambulatory costs (Table 1). On average, one ambulatory visit at FM cost less than that at most specialties. It might be attributed to fewer laboratory examinations at FM visits. Similar low cost per visit was also observed at visits to otorhinolaryngologists. URI, the most frequent disease seen at both specialties, might play a role [Liao et al. 2011].

The resources used in this study, which were compiled by the National Health Insurance Administration, have imposed limitations on our analysis. For instance, the results do not include self-pay procedures or medicines, such as expensive vaccines and cosmetic medicines. However, since the NHI program covers most diseases and requirements for preventive care, the above issues did not have a significant impact on the characteristics of ambulatory visits recorded in this study, although it should also be noted that our figures do not present a complete picture.

\section{Conclusions}

In Taiwan, FM is the most common utilized specialty of ambulatory care visits and acute URI is the most common diagnosis seen. The decreasing frequency of visits to FM by patients aged above 80 years is notable. The diseases managed differed between hospitals and FM clinics, especially with regard to chronic diseases and adult preventive care. In addition, the high proportion of antacids prescribed during visits requires further study.

\section{References}

1. Aboulghate A, Abel G, Lyratzopoulos G, Abdelmohsen A, Hamed AR, Roland M. 2013. Patterns of disease presentation and management in Egyptian primary care: findings from a survey of 2458 primary care patient consultations. BMC Family Practice 14:161. DOI: 10.1186/1471-2296-14-161.

2. American Institute in Taiwan. List of Physicians, Dentists and Medical Providers. Available at http://acs.ait.org.tw/medical-info.html (accessed 26 Apr 2015).

3. Baicker K, Chandra A. 2004. Medicare spending, the physician workforce, and beneficiaries' quality of care. Health Affairs Suppl Web Exclusives:W4-184-197. DOI: 10.1377/hlthaff.w4.184. 
243 4. Baicker K, Chandra A. 2009. Cooper's analysis is incorrect. Health Affairs 28:w116-w118. DOI: $10.1377 /$ hlthaff.28.1.w116.

5. Beckman A, Anell A. 2013. Changes inhealth care utilization following a reform involving choice and privatization in Swedish primary care: a five-year follow-up of GP-visits. BMC Health Services Research 13:452. DOI: 10.1186/1472-6963-13-452.

6. Bindman AB, Majeed A. 2003. Primary care in the United States: organisation of primary care in the United States. BMJ 326:631-634. DOI: 10.1136/bmj.326.7390.631.

7. Binns HJ, Lanier D, Pace WD, Galliher JM, Ganiats TG, Grey M, Ariza AJ, Williams R,

10. Chan DC, Hao YT, Wu SC. 2009. Polypharmacy among disabled Taiwanese elderly: a Primary Care Network Survey (PRINS) Participants. 2007. Describing primary care encounters: the Primary Care Network Survey and the National Ambulatory Medical Care Survey. Annals of Family Medicine 5:39-47. DOI: 10.1370/afm.620.

8. Cantrell R, Young AF, Martin BC. 2002. Antibiotic prescribing in ambulatory care settings for adults with colds, upper respiratory tract infections, and bronchitis. Clinical Therapeutics 24:170-182. DOI: 10.1016/S0149-2918(02)85013-5.

9. Chang CH, Stukel TA, Flood AB, Goodman DC. 2011. Primary care physician workforce and Medicare beneficiaries' health outcomes. JAMA 305:2096-2104. DOI: 10.1001/jama.2011.665.

longitudinal observational study. Drugs Aging 26:345-354. DOI: 10.2165/00002512200926040-00005.

11. Chen HY, Lin YH, Wu JC, Chen YC, Thien PF, Chen TJ, Yang SH, Chen JL, Lo SS. 2012. Characteristics of pediatric traditional Chinese medicine users in Taiwan: a nationwide cohort study. Pediatrics 129:e1485-e1492. DOI: 10.1542/peds.2011-3008.

12. Chen TJ, Chou LF, Hwang SJ. 2003. Application of a data-mining technique to analyze coprescription patterns for antacids in Taiwan. Clinical Therapeutics 25:2453-2463. DOI: 10.1016/S0149-2918(03)80287-4.

13. Chou WC, Cooney LM Jr, Van Ness PH, Allore HG, Gill TM. 2007. Access to primary care for Medicare beneficiaries. Journal of the American Geriatrics Society 55:763-768. DOI: 10.1111/j.1532-5415.2007.01154.x.

14. Cooper RA. 2009. States with more health care spending have better-quality health care: lessons about Medicare. Health Affairs 28:w103-w115. DOI: 10.1377/hlthaff.28.1.w103. 
274 15. Cooper RA. 2009. States with more physicians have better-quality health care. Health

275

276

277

278

279

280

281

282

283

284

285

286

287

288

289

290

291

292

293

294

295

296

297

298

299

300

301

302

303

304 Affairs 28:w91-w102. DOI: 10.1377/hlthaff.28.1.w91.

16. Cunningham CT, Cai P, Topps D, Svenson LW, Jetté N, Quan H. 2014. Mining rich health data from Canadian physician claims: features and face validity. BMC Research Notes 7:682. DOI: 10.1186/1756-0500-7-682.

17. Cypress BK. 1982. Drug utilization in office visits to primary care physicians: National Ambulatory Medical Care Survey, 1980. Advance data 86:1-16.

18. Cypress BK. 1983. Drug utilization in general and family practice by characteristics of physicians and office visits: National Ambulatory Medical Care Survey. Advance Data 87:1-12.

19. Cypress BK. 1983. Patterns of ambulatory care in general and family practice: The National Ambulatory Medical Care Survey. United States, January 1980 - December 1981. Vital and health statistics. Series 13, Data from the National Health Survey (73):i-iv, 1-60.

20. Ek S. 2013. Gender differences in health information behaviour: a Finnish population-based survey. Health Promotion International DOI: 10.1093/heapro/dat063.

21. Emmanuel SC, Phua HP, Cheong PY. 2004. 2001 Survey on primary medical care in Singapore. Singapore Medical Journal 45:199-213.

22. Galdas PM, Cheater F, Marshall P. 2005. Men and health help-seeking behaviour: literature review. Journal of Advanced Nursing 49:616-623. DOI: 10.1111/j.13652648.2004.03331.x.

23. Granja M, Ponte C, Cavadas LF. 2014. What keeps family physicians busy in Portugal? A multicentre observational study of work other than direct patient contacts. BMJ Open 4:e005026. DOI: 10.1136/bmjopen-2014-005026.

24. Jin K. 2014. The critical need to promote research of aging and aging-related diseases to improve health and longevity of the elderly population. Aging and Disease 6:1-5. DOI: 10.14336/AD.2014.1210.

25. Katz A, Halas G, Dillon M, Sloshower J. 2012. Describing the content of primary care: limitations of Canadian billing data. BMC Family Practice 13:7. DOI: 10.1186/1471-229613-7.

26. Lai MS, Chu CS, Lin SH, Lin MS. 1995. Prescribing patterns in primary health care in Taiwan. International Journal of Clinical Pharmacology and Therapeutics 33:437-441. 
305

306

307

308

309

310

311

312

313

314

315

316

317

318

319

320

321

322

323

324

325

326

327

328

329

330

331

332

333

334

335

27. Liao P, Ku M, Lue K, Sun H. 2011. Respiratory tract infection is the major cause of the ambulatory visits in children. Italian Journal of Pediatrics 37:43. DOI: 10.1186/1824-7288$37-43$.

28. Lin $\mathrm{CF}$, Wang $\mathrm{CY}$, Bai CH. 2011. Polypharmacy, aging and potential drug-drug interactions in outpatients in Taiwan: a retrospective computerized screening study. Drugs Aging. 28:219-225. DOI: 10.2165/11586870-000000000-00000.

29. Lynn AM, Lai LJ, Lin MH, Chen TJ, Hwang SJ, Wang PH. 2015. Pattern of ambulatory care visits to obstetrician-gynecologists in Taiwan: a nationwide analysis. International Journal of Environmental Research and Public Health 12:6832-6841. DOI: 10.3390/ijerph120606832.

30. Michael B. 2006. The Advanced Medical Home: A Patient-centered, Physician-guided Model of Health Care ; a Policy Monograph of the American College of Physicians. American College of Physicians.

31. Okkes IM, Polderman GO, Fryer GE, Yamada T, Bujak M, Oskam SK, Green LA, Lamberts H. 2002. The role of family practice in different health care systems: a comparison of reasons for encounter, diagnoses, and interventions in primary care populations in the Netherlands, Japan, Poland, and the United States. The Journal of Family Practice 51:72-73.

32. Oliver MI, Pearson N, Coe N, Gunnell D. 2005. Help-seeking behaviour in men and women with common mental health problems: cross-sectional study. The British Journal of Psychiatry 186:297-301. DOI: 10.1192/bjp.186.4.297.

33. Raza UA, Khursheed T, Irfan M, Abbas M, Irfan UM. 2014. Prescription patterns of general practitioners in Peshawar, Pakistan. Pakistan Journal of Medical Sciences 30:462-465. DOI: $10.12669 /$ pjms.303.4931.

34. Ryan S, Riley A, Kang M, Starfield B. 2001. The effects of regular source of care and health need on medical care use among rural adolescents. Archives of Pediatrics \& Adolescent Medicine 155:184-190. DOI: 10.1001/archpedi.155.2.184.

35. Shi L, Macinko J, Starfield B, Wulu J, Regan J, Politzer RJ. 2003. The relationship between primary care, income inequality, and mortality in the United States, 1980-1995. The Journal of the American Board of Family Practice 16:412-422. DOI:

10.3122/jabfm.16.5.412. 
336 36. Skinner J, Chandra A, Goodman D, Fisher ES. 2009. The elusive connection between health 337 care spending and quality. Health Affairs 28:w119-w123. DOI: 10.1377/hlthaff.28.1.w119.

338 37. Taiwan Medical Association. 2015. Stastics for 2014. p.18 \& p.161-p.162

339 Available at http://www.tma.tw/tma_stats_2014/2014_stats.pdf(accessed 26 June 2015)

340 38. Van Weel C, Del Mar CB. 2004. How should GPs be paid? The Medical Journal of $341 \quad$ Australia 181:98-99. 
Table $\mathbf{1}$ (on next page)

Ambulatory visits within Taiwan's National Health Insurance in 2012, stratified by specialty (1/500 sampling)

* The percentage of the ambulatory visits and cost claimed by specialty had been rounded, therefore the $\%$ in each of the table didn't give a total of $100 \%$ just. 
2

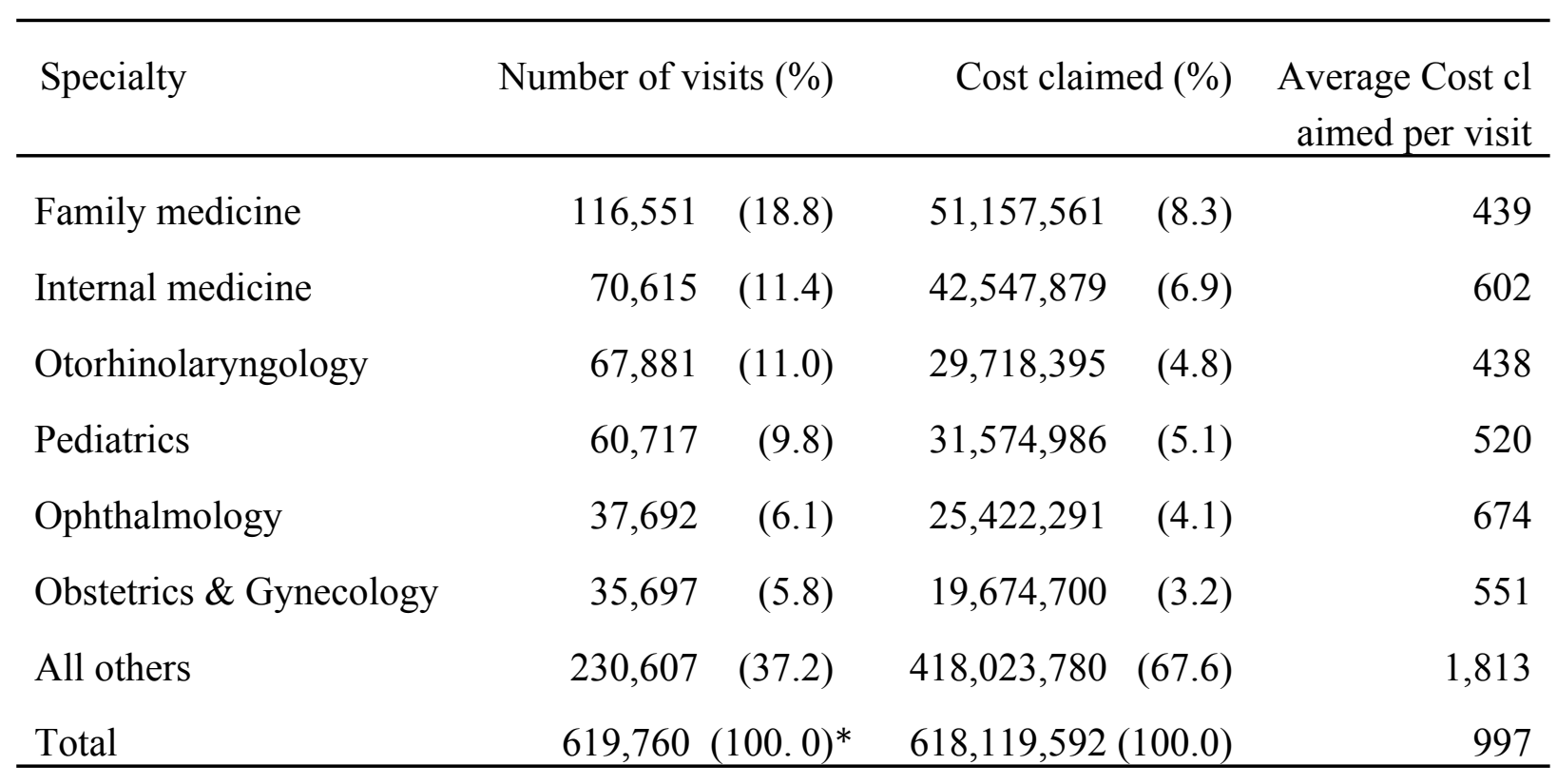

3 
Table 2 (on next page)

Ambulatory visits to family medicine specialists within Taiwan's National Health Insurance in 2012 , by disease group and hospital level (1/500 sampling)

* The International Classification of Diseases, 9th Revision, Clinical Modification. ** Including 48 home care visits. 


\begin{tabular}{|c|c|c|c|c|c|c|}
\hline $\begin{array}{l}\text { ICD9 } \\
\text { CM }^{*}\end{array}$ & Diagnosis group & $\begin{array}{l}\text { Total } \\
\mathrm{N}=116,551^{* *}\end{array}$ & $\begin{array}{l}\text { Academic } \\
\text { medical } \\
\text { center } \\
\mathrm{N}=2,637 \\
\end{array}$ & $\begin{array}{l}\text { Metropolitan } \\
\text { hospital } \\
\mathrm{N}=4,724 \\
\end{array}$ & $\begin{array}{l}\text { Local } \\
\text { community } \\
\text { hospital } \\
\mathrm{N}=4,346 \\
\end{array}$ & $\begin{array}{l}\text { Clinics } \\
\mathrm{N}=104,796\end{array}$ \\
\hline 465 & $\begin{array}{l}\text { Acute upper respiratory } \\
\text { infections }\end{array}$ & $22,461(13.1)$ & $36(1.3)$ & $104(2.2)$ & $167(3.8)$ & $19,458(18.5)$ \\
\hline 401 & Essential hypertension & $11,566(9.9)$ & $410(15.5)$ & $581(12.2)$ & $544(12.5)$ & $7,032(6.7)$ \\
\hline 780 & General symptoms & 8,097 (6.9) & $127(3.7)$ & $81(1.7)$ & $141(3.2)$ & $4,000(3.8)$ \\
\hline 466 & $\begin{array}{l}\text { Acute bronchitis \& } \\
\text { bronchiolitis }\end{array}$ & $6,909(5.9)$ & $15(0.5)$ & $46(0.9)$ & $99(2.2)$ & $5,070(4.8)$ \\
\hline 250 & Diabetes mellitus & $6,692(5.7)$ & $359(13.6)$ & $606(12.8)$ & $543(12.4)$ & $3,235(3.0)$ \\
\hline 272 & $\begin{array}{l}\text { Disorders of lipoid } \\
\text { metabolism }\end{array}$ & $5,980(5.1)$ & $217(8.2)$ & $238(5.0)$ & $110(2.5)$ & $1,026(0.9)$ \\
\hline 460 & Acute nasopharyngitis & $4,440(3.8)$ & $56(1.6)$ & $19(0.4)$ & $40(0.9)$ & $3,456(3.2)$ \\
\hline 535 & Gastritis \& duodenitis & $4,090(3.5)$ & $14(0.5)$ & $18(0.3)$ & $30(0.7)$ & $2,285(2.1)$ \\
\hline 784 & $\begin{array}{l}\text { Symptoms involving head } \\
\& \text { neck }\end{array}$ & $3,893(3.3)$ & $6(0.2)$ & $12(0.2)$ & $18(0.4)$ & $2,347(2.2)$ \\
\hline 729 & $\begin{array}{l}\text { Other disorders of soft } \\
\text { tissues }\end{array}$ & $3,778(3.2)$ & $7(0.2)$ & $9(0.1)$ & $33(0.7)$ & $2,463(2.3)$ \\
\hline
\end{tabular}


Table 3(on next page)

Top ten procedures and laboratory tests prescribed by family medicine specialists within Taiwan's National Health Insurance in 2012 (1/500 sampling)

* Taiwan's National Health Insurance code 
1

\begin{tabular}{llcr}
\hline NHI Code & Procedure & No. of visits & \% \\
\hline $09005 \mathrm{C}$ & Glucose & 4,269 & $3.7 \%$ \\
$09001 \mathrm{C}$ & Cholesterol, total & 2,719 & $2.3 \%$ \\
$09004 \mathrm{C}$ & Triglyceride & 2,599 & $2.2 \%$ \\
$09026 \mathrm{C}$ & S-GPT/ALT & 2,270 & $1.9 \%$ \\
$09015 \mathrm{C}$ & Creatinine & 2,047 & $1.8 \%$ \\
$06505 \mathrm{C}$ & HbAlc & 1,781 & $1.5 \%$ \\
$09044 \mathrm{C}$ & LDL-C & 1,586 & $1.4 \%$ \\
$48011 \mathrm{C}$ & Change dressing-small $(<10 \mathrm{~cm})$ & 1,455 & $1.2 \%$ \\
$09025 \mathrm{C}$ & S-GOT/AST & 1,195 & $1.0 \%$ \\
$09043 \mathrm{C}$ & HDL-C & 1,189 & $1.0 \%$ \\
\hline
\end{tabular}

2

3 
Table 4 (on next page)

Top ten drug classes prescribed by family medicine specialists within Taiwan's National Health Insurance in 2012 (1/500 sampling)

* Anatomical Therapeutic Chemical code 
1

\begin{tabular}{llcr}
\hline ATC Code & \multicolumn{1}{c}{ Drug classification } & No. of visits & \% \\
\hline R06A & Antihistamines for systemic use & 29,799 & 25.6 \\
M01A & Anti-inflammatory, non-steroids & 28,707 & 24.6 \\
N02B & Other analgesics and antipyretics & 28,516 & 24.5 \\
R05C & Expectorants & 16,263 & 14.0 \\
R05D & Cough suppressants & 15,121 & 13.0 \\
R05F & Cough suppressants \& expectorants combinations & 14,943 & 12.8 \\
A02A & Antacids & 14,558 & 12.5 \\
A03A & Drugs for functional bowel disorders & 10,997 & 9.4 \\
R03C & Adrenergics for systemic use & 8,894 & 7.6 \\
R01B & Nasal decongestants for systemic use & 8,886 & 7.6 \\
\hline
\end{tabular}


1

Age and sex distribution of patients at family medicine specialists within Taiwan's National Health Insurance in 2012 (1/500 sampling)

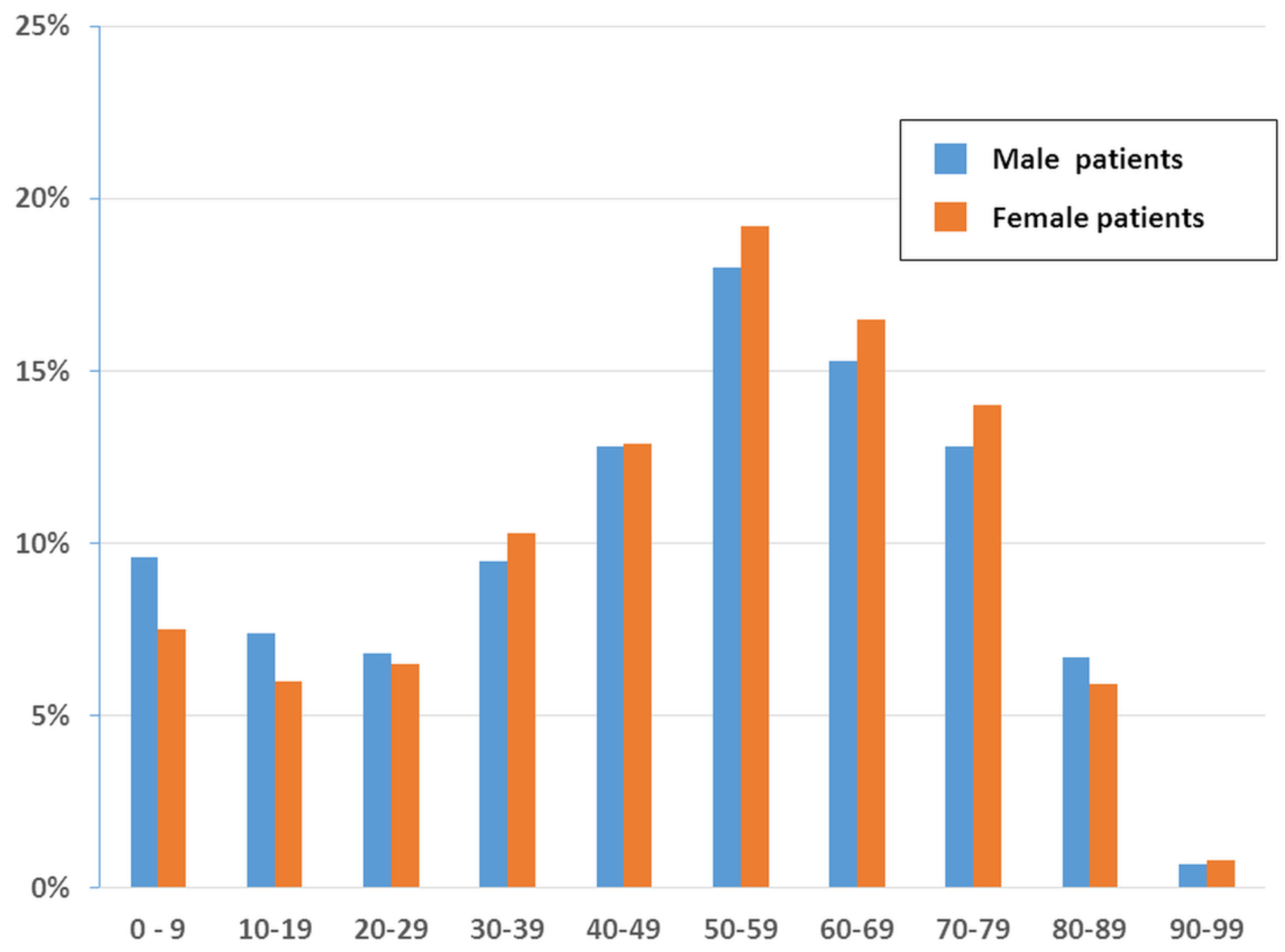


2

Age and sex distribution of family medicine specialists within Taiwan's National Health Insurance in 2012 (1/500 sampling)

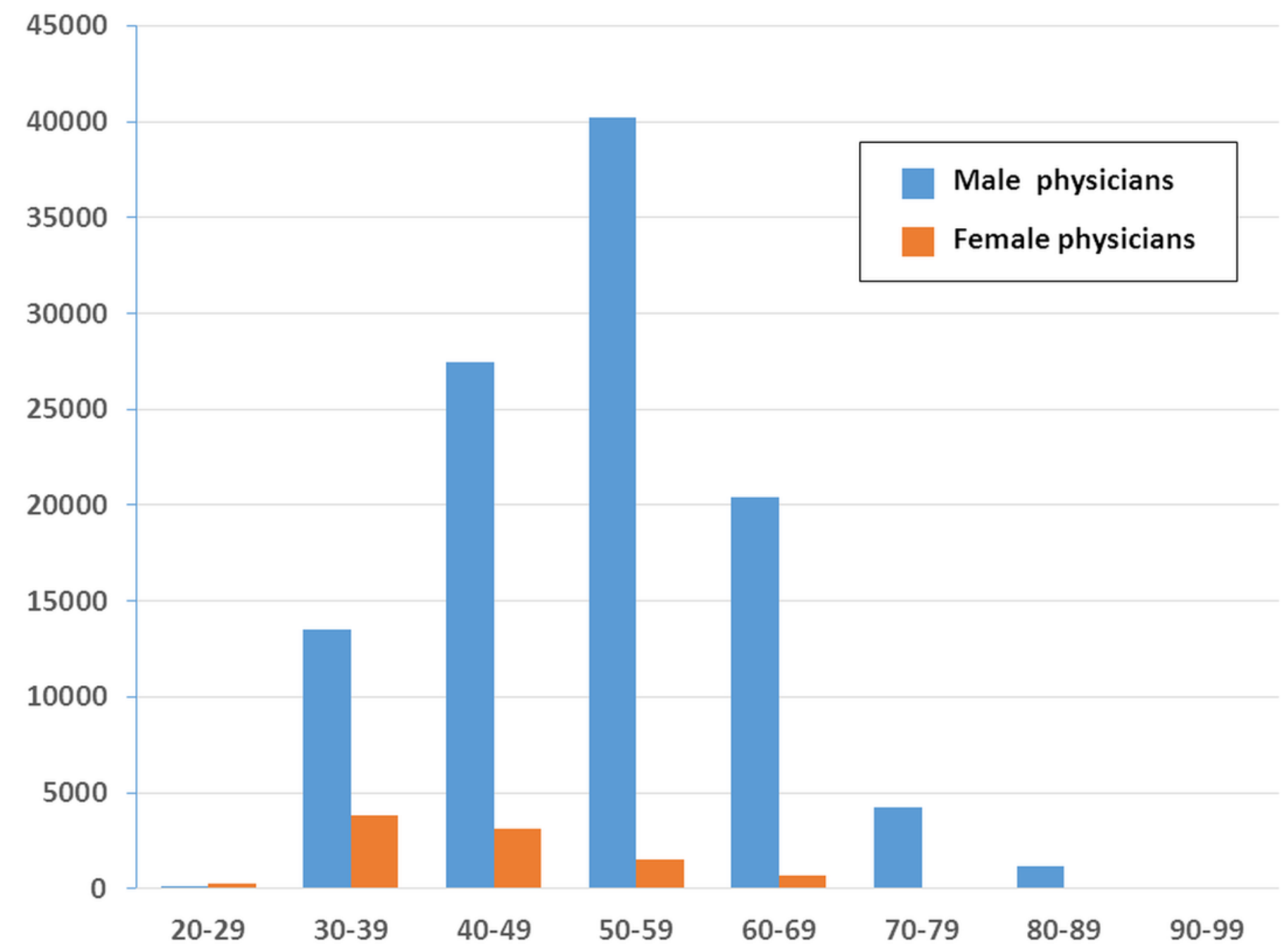

